\title{
ESTUDOS SOBRE A NUTRIÇÃO MINERAL DO CAFEEIRO. XXXI - INFLUENNCIA DO COBRE DO SUBSTRATO NO CRESCIMENTO E COMPOSIÇÃO MINERAL DO CAFEEIRO (Coffea arabica L.) VAR. MUNDO NOVO E CATUAI ${ }^{*}$
}

\author{
V.M. DE M. ANDRADE** \\ R.S. LOURENÇO*** \\ T. MURAOKA*** \\ E. MALAVOLTA****
}

RESUMO

A sensibilidade das variedades Catuaí e Mundo Novo ao nível de cobre no substrato foi estudada em condições controladas. Em solução nutritiva verificou-se que a primeira variedade parece ser mais resistente à toxidez. Ensaios com três tipos de solos mostraram que a elevação do $\mathrm{pH}$ a 6,5 e a adição conjunta de matéria orgânica neutralizam a toxidez correspondente a $200 \mathrm{ppm}$ do elemento no meio.

\section{INTRODUÇÃO}

1.1 Com a incidência da ferrugem do cafeeiro causada por Hemileia vastatrix Berk \& Br. tornou-se evidente, que, pelo menos a curto prazo, o controle químico por fungicidas cúpricos, acompanhado de novos processos de condução das lavouras, será o método mais viável de controle da enfermidade (CHAVES et al., 1971). Dai a possibilidade de, por causa do uso continuado de tais produtos, haver acúmulo de cobre no solo até ser atingida, concentração tóxica para o cafeeiro, tal como aconteceu nos pomares cítricos (REUTHER \& SMITH, 1954) e na videira (DROUINEAU \& MAZOYER, 1962).

1.2. Efeitos tóxicos do cobre sobre plantas novas de café foram observados e descritos por CASTILLO \& PARRA (1959), CASTRO (1961), TOKESHI et al. (1964) e HIROCE (1972) em viveiro e por ADUAYI (1971) em solução nutritiva.

1.3. Dai o fundamento do presente trabalho destinado a: (1) verificar o efeito do nivel de $\mathrm{Cu}$ do substrato sobre o crescimento, composição mineral e anatomia foliar do cafeeiro; (2) verificar a possibilidade de reduzir a disponibilidade do cobre no solo pela calagem e adição de matéria orgânica.

\footnotetext{
* Entregue para publicação em 30/12/1975. Parte da tese de doutorado do primeiro autor. Com ajuda do IBC, CNPq, CAPES, CNEN, BNDE e FAPESP. Apresentado no V Congr. Latinoamericano de Ciência do Solo (Medellin, Colômbia, set. de 1975).

* Fac. Agronomia e Med. Veterinária de Jaboticabal, S. Paulo.

** CENA - ESALQ-USP, Piracicaba.

*** Deptọ de Química e CENA - ESALQ-USP, Piracicaba.
} 


\section{MATERIAL E MÉTODOS}

\subsection{Ensaio em solução nutritiva}

Mudas de cafeeiro das variedades Mundo Novo e Catuai de 6 meses de idade foram cultivadas em solução nutritiva nọ 1 de HOAGLAND \& ARNON (1950) arejada continuamente, contida em recipientes de 2,5 litros de capacidade e renovada semanalmente, usando-se 4 repetiçб̃es dos tratamentos que foram os seguintes, em ppm de $\mathrm{Cu}$ :

$\begin{array}{lr}\text { tratamento } 1 \text { - } & 0,02 \\ \text { tratamento 2 - } & 0,20 \\ \text { tratamento } 3- & 2,00 \\ \text { tratamento } 4- & 20,00 \\ \text { tratamento } 5 \text { - } & 200,00 ;\end{array}$

$0,02 \mathrm{ppm}$ é a concentração do elemento recomendada por HOAGLAND \& ARNON (1950). Os sintomas de toxidez foram avaliados pela observação visual da parte aérea e das raízes. Para a observação das alterações histológicas o material foi coletado logo que apareciam os sintomas de toxidez, fazendo-se cortes e o preparo de lâminas permanentes. Foi determinado o peso da matéria seca das raízes, caule mais ramos e folhas; no material moído fez-se a determinação de macronutrientes e do cobre por métodos correntes.

\subsection{Ensaio em solos}

Foram usados $10 \mathrm{~kg} / \mathrm{vaso}$ de três tipos de solos, Regossol (R), Latossol fase arenosa (LFA) e Latossol roxo (LR), solos de regiões cafeeiras do Estado de São Paulo, Brasil. A adubação comum continha $\mathrm{N}, \mathrm{P}, \mathrm{K}, \mathrm{Ca}$ e $\mathrm{S}$. A calagem foi feita, com antecedência de 2 meses, sendo a dose de calcário calculada para elevar o $\mathrm{pH}$ a 6,5. A matéria orgânica como esterco de curral, fermentado, seco e moído foi aplicada nas doses de 0,20 e $200 \mathrm{ppm}$. Usaram-se 3 repetições dos tratamentos seguintes:

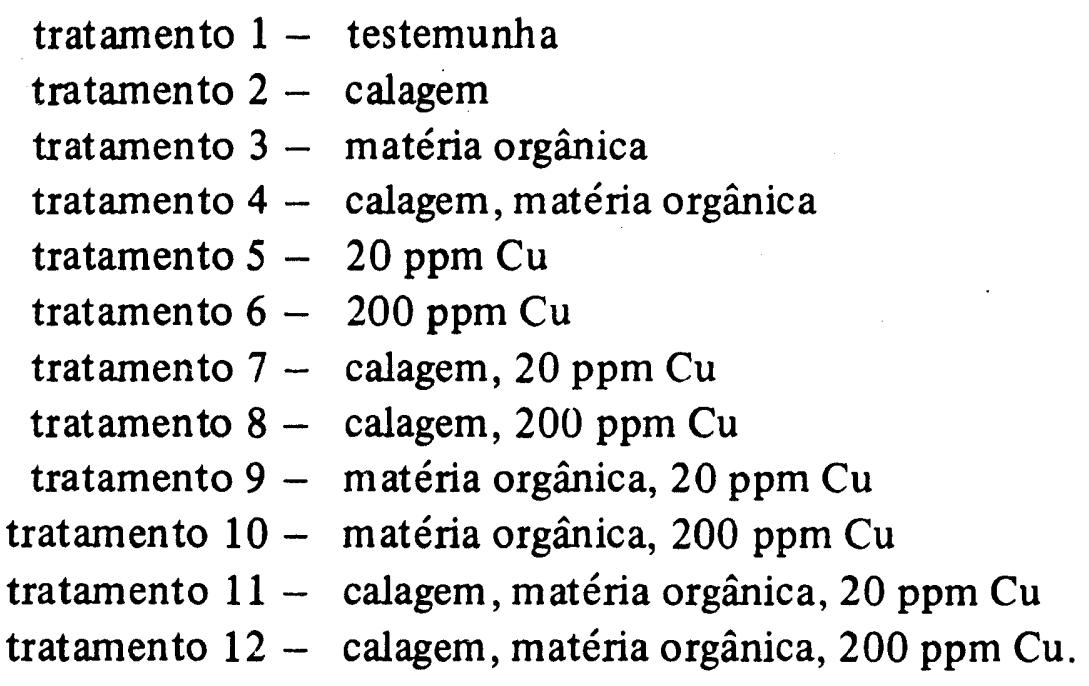

As plantas foram colhidas 18 meses depois do início do ensaio separando-se para tomada do peso da matéria seca e análise mineral as partes como no ensaio anterior. A atividade do $\mathrm{Cu}^{2+}$ foi determinada no LR segundo HANSEN et al. (1972). 


\section{RESULTADOS E DISCUSSÃO}

\subsection{Ensaio em solução nutritiva}

\subsubsection{Sintomas externos}

As plantas testemunhas da variedade Mundo Novo e da variedade Catuaí desenvolveram-se bem até o final do ensaio.

No tratamento em que foram aplicados $0,2 \mathrm{ppm}$ de cobre, houve apenas diminuição no crescimento da parte aérea e do sistema radicular, em comparação às testemu-. nhas para as duas variedades.

Com 2 ppm de cobre, 21 dias após o início do tratamento, as plantas da variedade Catuai apresentavam, na base do limbo das folhas inferiores, um amarelecimento em forma de $\mathrm{V}$, com o vértice voltado para o ápice da folha. Cessou o crescimento da parte aérea e do sistema radicular, e as plantas morreram antes de se completarem 65 dias de experimento. Para a variedade Mundo Novo, houve apenas diminuição no crescimento das plantas, em relação às que receberam menores doses de cobre. Também foi prejudi. cada a formação de raízes novas.

Observa-se que, a concentração de 2 ppm de cobre, as plantas da variedade Catuaí se mostraram mais sensiveis do que as da variedade Mundo Novo.

No tratamento correspondente à concentração de $20 \mathrm{ppm}$ de cobre na solução nutritiva, 13 dias após o início, as folhas pendiam paralelamente ao caule, e as inferiores apresentavam os sintomas de amarelecimento descritos anteriormente. As raizes deixavam de se desenvolver, e as plantas morriam antes de 60 dias. Estes sintomas oco reram nas duas varie dades.

As plantas que receberam $200 \mathrm{ppm}$ de cobre, perderam totalmente as folhas, 13 dias a contar do início dos tratamentos. Com 5 dias, as plantas da variedade Mundo Novo já haviam perdido as folhas maduras, e nas plantas da variedade Catuaí, as folhas inferiores estavam murchas. Nas duas variedades, paralizou o crescimento das raizes, que se mostravam escurecidas. Antes de 20 dias, a contar do início do ensaio, as plantas de ambas as variedades já haviam morrido.

\subsubsection{Sintomas internos}

O estudo das alterações anatômicas provocadas por doses altas de cobre, foi feito em folhas de plantas cultivadas na presença de 200 ppm do elemento. Compararam-se áreas normais, que não apresentavam sintomas, com áreas afetadas em diversos graus.

\section{a - Áreas sem sintomas}

a.1. Epiderme adaxial - células com forma geralmente retangular, sendo os lados maiores (membranas periclimais), paralelos à superfície foliar. Conteúdo celular hialino; membranas periclinais externas revestidas por cutícula delgada. Membranas celulares também hialinas, com coloração levemente esverdeada. 
a.2. Parênquima paliçádico - constituído por uma camada de células alongadas, perpendiculares à superfície da folha, cheias de cloroplastos. $O$ comprimento das células do parênquima paliçádico correspondia a aproximadamente um terço da espessura do mesófilo. Apresentavam-se unidas lateralmente em quase toda sua extensão, e, pela porção inferior uniam-se às células do parênquima lacunoso.

a.3. Parênquima lacunoso - células com forma irregular, alongadas, dispostas paralelamente à superfície do limbo. Cloroplastos abundantes, porém em número inferior ao das células do parênquima paliçádico. Lacunas relativamente grandes.

a.4. Epiderme abaxial - semelhante à epiderme adaxial, porém com células mais baixas e mais alongadas.

a.5. Cloroplastos - forma variando de ovalada a arredondada, com cerca de 0,3 micras no maior diâmetro, e coloração verde forte. Preenchiam quase toda a célula no parênquima paliçádico e apareciam dispersos nas células do parênquima lacunoso.

a.6. Gotas lipídicas - presentes na maioria das células do mesófilo, ocupando posição quase central. Contorno circular e tamanho variando de 0,7 a 1,3 micras, predominando as gotas maiores.

A anatomia da folha na área sem sintoma assemelha-se à anatomia de folhas de cafeeiro, descrita por MENARD (1956) e por ACORSI \& HAAG (1959), ambas referentes a plantas cultivadas em soluçã̉o nutritiva completa.

b - Área próxima ao sintoma

b.1. Epiderme - ambas as epidermes semelhantes àquelas da área sem sintomas.

b.2. Parênquimas paliçádico e lacunoso - as células não diferiam, no que diz respeito à forma e conteúdo, daquelas da região sem sintoma.

b.3. Cloroplastos - número reduzido nos dois parênquimas, aglomerados em um canto da célula, ou dispostos na periferia, acompanhando o contorno. No parênquima lacunoso eram deformados, irregulares, alongados ou recurvados, de coloração verde mais claro do que na região sem sintoma.

b.4. Gotas lipídicas - apareciam raramente, tanto no parênquima paliçádico, como no lacunoso. Quando presentes, eram de diâmetro menor, ocupando posição quase central na célula.

\section{c - Área com sintomas menos acentuados}

c.1. Epiderme - forma das células não alterada em ambas as epidermes. Conteúdo celular mais escuro, pardacento, na epiderme adaxial. Na abaxial conteúdo hialino, semelhan te ao das células da área sem sintoma.

c.2. Mesófilo - parênquima paliçádico com células de forma normal, e conteúdo celular pardo-claro. No parênquima lacunoso células com forma normal e conteúdo hialino.

c.3. Cloroplastos - com coloração pardo-escura no parênquima paliçádico, sem alteração na forma, havendo poucos cloroplastos irregulares. No parênquima lacunoso con- 
servam-se verdes, porém, com forma irregular, recurvados, em algumas células. O tamanho era aproximadamente o mesmo daqueles da área sem sintoma, e seu número reduzido no parênquima lacunoso.

c.4. Gotas lipídicas - presentes na maioria das células do mesófilo, com o mesmo tamanho e posição das gotas lipídicas presentes nas células da região sem sintomas. Em relação a estas últimas, um pouco mais opacas.

d - Área com sintomas acentuados

A espessura da folha era reduzida nessa região.

d.1. Epiderme - células da epiderme adaxial deformadas, apresentando contorno irregular e conteúdo mais escuro, pardo. Membranas celulares e cutícula também pardo-escuro. Epiderme abaxial com células não muito modificadas, apenas em alguns locais um pouco comprimidas.

d.2. Mesófilo - parênquima paliçádico com células pardo-escuro, deformadas, não tendo sido possível precisar seu contorno. Parênquima lacunoso composto de células com conteúdo hialino, porém mais escuro, pardo, nas células adjacentes à epiderme abaxial. Estas últimas eram deformadas, comprimidas.

d.3. Cloroplastos - não foi possível distingui-los no parênquima paliçádico. No lacunoso eram irregulares, alongados, recurvados, e em número bem menor, aglomerados a um canto da célula.

d.4. Gotas lipídicas - não foi possivel distingui-las no parênquima paliçádico. Apareciam em raras células no parênquima lacunoso, mais opacas do que nas células das áreas sem sintomas.

Havia áreas com sintomas ainda mais acentuados, com os tecidos necrosados, e a espessura da folha bem reduzida. Células de forma irregular, com membranas tortuosas e conteúdo pardo-escuro.

Verificou-se que as alterações ocorreram principalmente nos cloroplastos, com modificação no número, forma e coloração, mesmo em áreas com sintomas pouco acentuados. À medida que progrediram os sintomas, alterações surgiram também no conteúdo celular e na forma das células epidérmicas e do mesófilo. MENARD (1956) observou sintomas semelhantes em folhas de cafeeiro cultivado em solução nutritiva com 0,5 ppm de cobre. Também ACCORSI \& HAAG (1959), descrevem alterações semelhantes em cafeeiro cultivado em solução nutritiva com excesso de $\mathrm{N}, \mathrm{K}, \mathrm{Mg}$ e $\mathrm{S}$.

\subsubsection{Crescimento}

As determinações de matéria seca encontram-se na Tabela 3.1. por onde se vê que o crescimento diminui com a elevação do nivel de $\mathrm{Cu}$ no substrato-sendo nos termos relativos maior a diminuição observada em Mundo Novo que em Catuaí. O efeito depressivo do alto nivel de cobre no crescimento já fora descrito por MENARD (1956), CASTILLO \& PARRA (1959) e AOUAYI (1971). As pequenas diferenças existentes entre as doses de crescimento relativas às duas concentrações mais altas empregadas deve-se ao fato de a elevada toxidez ter-se manifestado quase simultaneamente nesses tratamentos o que obrigou a colheita das plantas. 


\begin{tabular}{lrcccc}
\hline & \multicolumn{5}{c}{ p.p.m.Cu } \\
Parte & 0,02 & 0,20 & 2,00 & 20,00 & 200,00 \\
\hline & & \multicolumn{4}{c}{ Mundo Novo } \\
Raízes & 2,1 & 1,2 & 1,0 & 0,2 & 0,3 \\
Caules e Ramos & 6,7 & 4,7 & 4,6 & 1,0 & 1,0 \\
Folhas & 10,1 & 7,8 & 4,6 & 2,2 & 2,1 \\
Total & 18,9 & 13,7 & 10,2 & 3,4 & 3,4 \\
& & & Catuaí & 0,4 & 0,3 \\
Raízes & 2,5 & 2,2 & 0,5 & 1,9 & 1,6 \\
Caules e Ramos & 5,0 & 5,1 & 1,7 & 1,9 & 3,1 \\
Folhas & 9,1 & 10,1 & 3,0 & 1,8 & 5,0 \\
Total & 16,6 & 17,4 & 5,2 & 4,1 & \\
\hline
\end{tabular}

QUADRO 3.1 - Produção de matéria seca em função de níveis de cobre na solução nutritiva (g/planta)

\subsubsection{Teores minerais}

As concentrações de macronutrientes nas folhas aparecem na Tabela 3.2. A análise estatística mostrou existirem correlações significativas entre nivel de cobre no meio e teores foliares de $\mathrm{N}, \mathrm{K}$ e $\mathrm{Ca}$. De um modo geral nota-se a tendência para aumentar $\mathrm{o}$ teor dos elementos na folha quando cresce o suprimento de cobre o que pode ser devido a um efeito inverso do de diluição causado pela progressiva redução no crescimento (ver 3.1.3.).

\begin{tabular}{llllll}
\hline & & \multicolumn{4}{c}{ p.p.m. Cu } \\
Elemento (\%) & 0,02 & 0,20 & 2,00 & 20,00 & 200,00 \\
\hline Nitrogênio (N) & & & & & \\
$\quad$ Mundo Novo & 3,55 & 3,58 & 3,22 & 6,10 & - \\
$\quad$ Catuaí & 4,49 & 4,14 & 4,04 & 3,47 & 5,33 \\
$\begin{array}{l}\text { Fósforo (P) } \\
\quad \text { Mundo Novo }\end{array}$ & 0,24 & 0,12 & 0,06 & 0,05 & - \\
$\quad$ Catuaí & 0,24 & 0,22 & 0,16 & 0,16 & 0,26 \\
$\begin{array}{l}\text { Potássio (K) } \\
\quad \text { Mundo Novo }\end{array}$ & 2,38 & 1,75 & 1,72 & 6,20 & - \\
$\quad$ Catuaí & 2,73 & 2,63 & 5,31 & 8,12 & 8,32 \\
$\begin{array}{l}\text { Cálcio (Ca) } \\
\quad \text { Mundo Novo }\end{array}$ & 0,31 & 0,22 & 0,31 & 0,72 & - \\
$\quad$ Catuaí & 0,71 & 0,75 & 0,82 & 0,46 & 0,52 \\
$\begin{array}{l}\text { Magnésio (Mg) } \\
\quad \text { Mundo Novo }\end{array}$ & 0,16 & 0,13 & 0,09 & 0,28 & - \\
$\quad$ Catuaí & 0,31 & 0,30 & 0,38 & 0,28 & 0,47 \\
Enxofre (S) & & & & & \\
$\quad$ Mundo Novo & 0,38 & 0,08 & 0,11 & 0,25 & - \\
$\quad$ Catuaí & 0,38 & 0,36 & 0,27 & 0,25 & 0,41 \\
\hline
\end{tabular}

QUADRO 3.2 - Teores foliares de macronutrientes em função do nível de cobre na solução nutritiva. 
A Tabela 3.3. fornece as doses relativas às quantidades de cobre encontradas nas diferentes partes dos cafeeiros das duas variedades. Verifica-se significativa diferença no comportamento das duas variedades: Mundo Novo concentrou menos cobre nas raízes e translocou mais para a parte aérea o que ajuda a explicar a sua maior sensibilidade à toxidez do elemento (3.1.1.).

\begin{tabular}{lcccc}
\hline Tratamento (ppm) & raízes & $\begin{array}{c}\text { caules mais } \\
\text { ramos }\end{array}$ & folhas & Total \\
\hline $\begin{array}{l}\text { 0,02 } \\
\text { Mundo Novo }\end{array}$ & 0,05 & 0,10 & 0,11 & 0,27 \\
$\quad$ Catuaí & 0,05 & 0,06 & 0,09 & 0,21 \\
$\begin{array}{l}0,20 \\
\quad \text { Mundo Novo }\end{array}$ & 0,04 & 0,07 & 0,09 & 0,21 \\
$\quad$ Catuaí & 0,14 & 0,05 & 0,07 & 0,26 \\
$\begin{array}{l}\text { 2,00 } \\
\quad \text { Mundo Novo }\end{array}$ & 0,19 & 0,10 & 0,07 & 0,36 \\
$\quad$ Catuaí & 0,67 & 0,15 & 0,08 & 0,91 \\
$\begin{array}{l}\text { 20,00 } \\
\quad \text { Mundo Novo }\end{array}$ & 1,22 & 0,62 & 0,24 & 2,10 \\
$\quad$ Catuaí & 4,49 & 0,82 & 0,13 & 5,44 \\
$\begin{array}{l}\text { 200,00 } \\
\text { Mundo Novo }\end{array}$ & - & 2,04 & - & 2,04 \\
$\quad$ Catuaí & 4,13 & 4,74 & 1,48 & 10,36 \\
\hline
\end{tabular}

QUADRO 3.3 - Quantidades de cobre contidas nas diversas partes das plantas (mg)

\subsection{Ensaios em solos}

Os dados de crescimento acham-se resumidos na Tabela 3.4. Verifica-se que $20 \mathrm{ppm}$ de $\mathrm{Cu}$ não tiveram efeito tóxico enquanto $200 \mathrm{ppm}$ reduziram a prdução de matéria seca a $1 / 3,1 / 2$ e $2 / 3$, respectivamente no Ressol, Latossol fase arenosa e Latossol roxo. Somente a aplicação conjunta do calcário e da matéria orgânica conseguiu eliminar o efeito tóxico do alto nível de $\mathrm{Cu}$ nos três solos. A determinação de $\mathrm{pCu}$ com ajuda do eletrodo específico mostrou que o valor caiu de muito maior que 10,0 para 6,9 plantas em conseqüência desse tratamento. A análise mostrou dados consistentes (Tabela 3.5.). 


\begin{tabular}{|c|c|c|c|}
\hline Tratamento & \multicolumn{3}{|c|}{$\begin{array}{l}\text { Matéria seca (g/planta) } \\
\text { Latossol }\end{array}$} \\
\hline Testemunha & 17,0 & 23,4 & 26,6 \\
\hline Calcário & 8,7 & 14,1 & 29,2 \\
\hline Matéria orgânica & 18,1 & 14,4 & 18,6 \\
\hline Cal. + mat. orgânica & 12,7 & 17,1 & 21,8 \\
\hline $20 \mathrm{ppm} \mathrm{Cu}$ & 27,5 & 27,9 & 27,4 \\
\hline $200 \mathrm{ppm} \mathrm{Cu}$ & 6,8 & 13,8 & 19,8 \\
\hline $\mathrm{Cal} .+20 \mathrm{ppm} \mathrm{Cu}$ & 10,3 & 21,7 & 21,6 \\
\hline $\mathrm{Cal} .+200 \mathrm{ppm} \mathrm{Cu}$ & 4,3 & 14,5 & 26,0 \\
\hline Mat. org. $+20 \mathrm{ppm} \mathrm{Cu}$ & 27,9 & 25,4 & 19,6 \\
\hline Mat. org. $+200 \mathrm{ppm} \mathrm{Cu}$ & 6,9 & 22,4 & 21,2 \\
\hline $\mathrm{Cal}+$ mat. org. $+20 \mathrm{ppm} \mathrm{Cu}$ & 17,3 & 22,5 & 23,8 \\
\hline $\mathrm{Cal} .+$ mat. org. $+200 \mathrm{ppm} \mathrm{Cu}$ & 15,3 & 19,5 & 24,6 \\
\hline
\end{tabular}

QUADRO 3.4 - Efeito de calagem e de matéria orgânica na diminuição do efeito tóxico do cobre.

\begin{tabular}{lccr}
\hline Tratamento & Raízes & $\begin{array}{c}\text { Caule }+ \\
\text { ramos }\end{array}$ & Folhas \\
\hline Testemunha & 56 & 32 & 28 \\
$20 \mathrm{ppm} \mathrm{Cu}$ & 88 & 40 & 32 \\
$200 \mathrm{ppm} \mathrm{Cu}$ & 192 & 36 & 52 \\
$20 \mathrm{ppm} \mathrm{Cu}+$ Cal. + mat. org. & 56 & 28 & 28 \\
$200 \mathrm{ppm} \mathrm{Cu}+$ Cal. + mat. org. & 88 & 32 & 28 \\
\hline
\end{tabular}

QUADRO 3.5 - Teores de cobre nas diversas partes da planta (média de três solos) (p.p.m.)

\section{RESUMO E CONCLUSÓES}

1 - O presente trabalho teve a finalidade de estudar o efeito do cobre no substrato sobre o crescimento e composição mineral do cafeeiro novo tendo em vista um possível efeito prejudicial dos resíduos acumulados no solo como conseqüência do tratamento contra a ferrugem.

2 - Plantas jovens das variedades Mundo Novo e Catuaí foram cultivadas em solução nutritiva com niveis de $\mathrm{Cu}^{2+}$ que variaram entre 0,02 e $200 \mathrm{ppm}$.

3 - Verificou-se que os sintomas fitotóxicos são: escurecimento e paralização do crescimento radicular; encurtamento das raízes secundárias; murchamento, necrose e queda das folhas; anormalidades na epiderme, parênquimas e cloroplastos.

4 - O nivel de transição entre concentração não prejudicial e toxidez nas folhas está em torno de $30 \mathrm{ppm}$.

5 - A variedade Mundo Novo mostrou mais sensível à toxidez de $\mathrm{Cu}$ ao que parece por translocar maior proporção do elemento absorvido.

6 - Em condições de solo verificou-se que a aplicação de matéria orgânica e de calcário elimina a toxidez do cobre (correspondente a uma concentração de 200 ppm), por reduzir a atividade do elemento $(\mathrm{pCu})$. 


\section{SUMMARY}

\section{STUDIES ON THE MINERAL NUTRITION OF THE COFFEE PLANT. XXXI - INFLUENCE OF COPPER IN THE SUBSTRATE ON GROWTH AND MINERAL COMPOSITION, VAR. MUNDO NOVO AND CATUAI}

This work was designed to study the effect of copper in the medium on growth and mineral composition of the coffee plant, bearing in mind the possibility of accumulation of toxic residues in the soil as a consequence of the treatments against rust.

- Young plants of the varieties Mundo Novo and Catuai were grown in nutrient solution in the presence of $\mathrm{Cu}$ concentrations from 0.02 to $200 \mathrm{ppm}$. Toxic effects were found to be darkening and cessation of root growth; wilt, necrosis and leaf drop; abnormalities in the epidermis, parenchyma and chloroplasts. The threshold level for copper toxicity in around $30 \mathrm{ppm}$ in the leaves. Mundo Novo seems to be more sensitive to copper toxicity.

- Under soil conditions it was found that the joint use of lime and stable manure eliminates the toxicity of an application of $200 \mathrm{ppm}$ of copper.

\section{LITERATURA CITADA}

ACCORSI, W.R. \& HAAG, H.P., 1959. Alterações morfológicas do cafeeiro cultivado em solução nutritiva decorrentes das deficiências e excessos de macronutrientes. Anais da E.S.A. "Luiz de Queiroz", 16:17-36.

ADUAYI, E.A., 1971. The effects of copper sprays on the growth and major nutrient contents of coffee seedlings grown in nutrient solutions. Turrialba, 21:53-57.

CASTIllo, J. \& PARRA, H.J., 1959. Efecto toxico del cobre en semilleros de cafe. Cenicafé, 10:109-117.

CASTRO, F.S., 1961. Semilleros e germinadores de café. Agri. Trop., 17:317-324.

CHAVES, G.M., MATSUOKA, K, CARVALHO, M.G. \& CRUZ FILHO, J., 1971. Ferrugem do Cafeeiro (Hemileia vastatrix Berk \& Br.). Seiva, 73:120-137.

DROUINEAU, G. \& MAZOYER, R., 1962. Contribution a l'étude de la toxicité du cuivre dans les sols. Ann. Agron., 13:31-53.

HANSEN, E.H., LAMM, C.G. \& RUZICKA, J., 1972. Selectrode the universal ion selective solid state electrode. Part II. Anal. Chem. Acta, 59:403-429.

HIROCE, R., 1972. A falta que o cobre faz ao café. Supl. Agr. "O Estado de São Paulo, 871.

HOAGLAND, D.R. \& ARNON, D.I., 1950. The water culture method for growing plants without soil. Calif. Agr. Exp. Sta. Cir., 347.

MENARD, L.N., 1956. Efeitos do fósforo e de alguns micronutrientes no crescimento e composição química do cafeeiro cultivado em solução nutritiva. Tese de Doutoramento, E.S.A. "Luiz de Queiroz", USP, Piracicaba.

REUTHER, W. \& SMITH, P.F., 1954. Toxic effects of accumulated copper in Florida soils. Soil. Sci. Soc. Florida. Proc., $14: 17-23$.

TOKESHI, H., GALlI, F., CARVALHO, P.C.T., BALMER, E., KIMATI, H., NAMEKATA, T., CARDOSO, C.O.N. \& SANCHES, B.R., 1964. Ensaio sobre o controle de "damping-off" do cafeeiro. Anais da E.S.A. "Luiz de Queiroz", $21: 140-149$. 

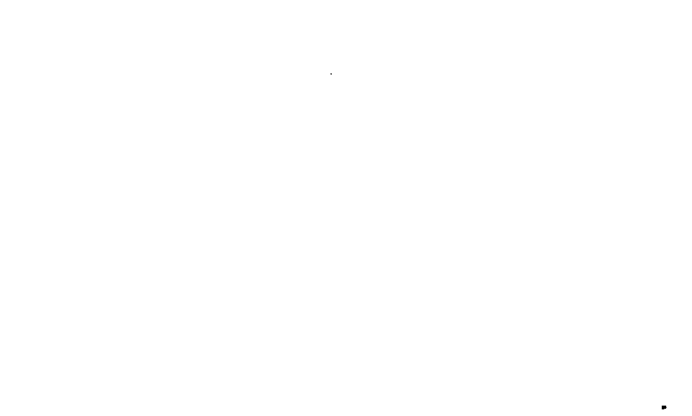